\title{
BMJ Open Association between traffic-related air pollution and asthma in preschool children in a national Japanese nested case-control study
}

Hideki Hasunuma, ${ }^{1,2}$ Tosiya Sato, ${ }^{3}$ Tsutomu Iwata, ${ }^{4}$ Yoichi Kohno, ${ }^{5}$ Hiroshi Nitta, ${ }^{6}$ Hiroshi Odajima, ${ }^{7}$ Toshimasa Ohara, ${ }^{6}$ Takashi Omori, ${ }^{8}$ Masaji Ono, ${ }^{6}$ Shin Yamazaki, ${ }^{6}$ Masayuki Shima ${ }^{1}$

To cite: Hasunuma $\mathrm{H}$, Sato $\mathrm{T}$, Iwata T, et al. Association between traffic-related air pollution and asthma in preschool children in a national Japanese nested case-control study. BMJ Open 2016;6:e010410. doi:10.1136/bmjopen-2015010410

- Prepublication history and additional material is available. To view please visit the journal (http://dx.doi.org/ 10.1136/bmjopen-2015010410).

Received 30 October 2015 Revised 6 January 2016 Accepted 26 January 2016

CrossMark

For numbered affiliations see end of article.

Correspondence to Dr Masayuki Shima; shima-m@hyo-med.ac.jp

\section{ABSTRACT}

Objectives: There has been little study on the effect of traffic-related air pollution on the incidence and persistence of asthma in preschool children. We evaluated the association of exposure to traffic-related air pollution with the incidence/persistence of asthma during the first 3 years of life using a population-based study.

Methods: A baseline survey was conducted in 11/2year-old children ( $n=63266$ ). A follow-up survey at 3 years of age $(n=43343)$ identified new-onset asthma cases $(n=853)$ and persistence of asthma $(n=214)$. In the prevalence/persistence study, the outdoor concentrations of nitrogen oxides (NOx) and elemental carbon (EC) at home during the first $1 \frac{1}{2}$ years of life were estimated by a dispersion model. In the nested case-control study, which regarded incidence of asthma as cases, the personal exposure levels were estimated by dispersion model including time-activity pattern.

Results: There was no statistically significant association between the incidence of asthma between age $1 \frac{1}{2}$ and 3 years and personal exposure levels to NOx nor EC. However, the persistence of asthmatic symptoms (between $1 \frac{1}{2}$ and 3 years) was significantly associated with outdoor concentrations of NOx. ORs for the persistence of asthmatic symptoms were 6.02 (95\% Cl 1.51 to 23.92) for the comparison between the upper 5th and lower 25th centiles of NOx.

Conclusions: While no statistically significant association was observed for the incidence of asthma, the persistence of asthmatic symptoms in preschool children was significantly associated with traffic-related air pollution. This supports its importance as a risk factor in childhood airway disease.

\section{INTRODUCTION}

Epidemiological studies have suggested associations between traffic-related air pollution and incidence of asthma. ${ }^{1-4}$ However, despite the fact that the incidence of asthma is also

\section{Strengths and limitations of this study}

- This study examined the association between traffic-related air pollution and the incidence/persistence of asthma during the preschool period, in a longitudinal way across Japan.

- The persistence of asthmatic symptoms between $1 \frac{112}{2}$ and 3 years was significantly associated with outdoor concentrations of nitrogen oxides, as estimated by the dispersion model.

- The inherent difficulty of evaluating asthma during the preschool period may lead to observation of no association between traffic-related air pollution and new-onset asthma.

high in preschool children, there have been only a limited number of studies investigating the association between traffic-related air pollution and the incidence of asthma during the preschool period.

In addition, previous epidemiological studies shared two common issues. The first issue was the evaluation of asthma in preschool children. The lack of standardised diagnostic criteria for infantile asthma makes it inherently difficult to evaluate asthma in preschool children. The second issue was the accuracy of exposure assessment. Many of the relevant studies have introduced measures to adequately estimate outdoor concentrations of traffic-related pollution such as land-use regression (LUR) or dispersion models. In order to provide a more adequate assessment, however, it is applicable to evaluate the validity of estimated concentrations in comparison with measured concentrations.

In the past few years, the results of epidemiological studies conducted in Germany, British Columbia, Sweden, the Netherlands and Italy that also overcame these two issues have been published. $^{5-10}$ Some studies 
(British Columbia, GINI and LISA) have claimed that the association between air pollution and the incident of infantile asthma is found to be statistically significant. ${ }^{5}{ }^{6}$ BAMSE (Swedish abbreviation for Children, Allergy, Milieu, Stockholm, Epidemiological Survey) and PIAMA (Prevention and Incidence of Asthma and Mite Allergy) studies did not find a significant association with asthma incidence in preschool children, but one that was significant at age $8 .^{78}$ Other studies (Italy), however, have found the relation somewhat weak, ${ }^{9}$ while studies in Sweden ${ }^{10}$ even asserted that no relationship between them was observed. Thus, the results have been contradictory and demand that further epidemiological research is needed.

In Japan, the Study on Respiratory Disease and Automobile Exhaust (SORA project) was established by the Ministry of the Environment Government of Japan to overcome these three problems. In the SORA project, we developed an exposure estimation model whose performance was confirmed by field measurement, and a questionnaire which confirmed the validity of the evaluation of infantile asthma. This paper therefore shows the results of a nested case-control study conducted in 20062010 to determine whether exposure to traffic-related air pollution was associated with the incidence/persistence of asthma during the first 3 years of life.

\section{MATERIALS AND METHODS}

\section{Study design}

This study of preschool children consisted of a baseline survey performed at the age of $1 \frac{1}{2}$ years, a follow-up survey at 3 years of age and a nested case-control study (figure 1). In the baseline survey at age $1 \frac{1 / 2}{2}$ years, the outcome was the prevalence of asthma. In the follow-up survey at age 3 years, the incidence of asthma was identified as well as the persistence of asthmatic symptoms during the follow-up period. In the nested case-control study, participants with new-onset asthma between the ages of $1 \frac{1}{2}$ and 3 years were regarded as cases, and participants randomly selected from those who did not develop asthma during this period were regarded as controls. An interview, blood examination and mite allergen test were conducted. The written informed consent was obtained from all parents of the participants.

\section{Study area}

Heavy-traffic roads with diesel particulate matter emission $\geq 8000 \mathrm{~g} / \mathrm{km} /$ day were selected using road traffic census data from 1999 (Ministry of Land, Infrastructure, Transport and Tourism, Japan $)^{11}$ and regional mesh statistics of the census in fiscal year 2000 (Ministry of Internal Affairs and Communications, Japan). ${ }^{12}$ Areas where the percentage of 1-year-old children living within $50 \mathrm{~m}$ of heavy-traffic roads was estimated to be high were selected from all municipalities in Japan.

As a result, nine cities and wards (Chiba City, Itabashi Ward, Suginami Ward, Setagaya Ward, Kawasaki City,
Yokohama City, Nagoya City, Osaka City and Kobe City) were selected as survey areas. The percentage of 1year-old children living within $50 \mathrm{~m}$ of heavy-traffic roads was estimated to be about $4 \%$. The survey areas are shown in online supplementary figure S1.

\section{Baseline survey}

As a baseline survey, a questionnaire survey of all $1 \frac{1}{2-y e a r-o l d ~ c h i l d r e n ~ l i v i n g ~ i n ~ t h e ~ s u r v e y ~ a r e a s ~ w a s ~ p e r-~}$ formed. The participants were identified every month in 2006-2008, based on the resident registration of the local governments. A questionnaire was mailed to each home of the participants together with a notice of a health check-up examination for 11/2-year-old children $(\mathrm{n}=102631)$ by the local governments. Their parents completed the questionnaire and brought it with them when their children underwent the health check-up examination. Replies were obtained from the parents of 63266 participants $(61.6 \%)$.

The questionnaire items were gender, familial smoking habits, the house structure, years of residence, presence/ absence of pets, feeding method during the first 3 months of life, history of respiratory diseases, and parental history of allergic diseases. Concerning respiratory symptoms, 'asthma' and 'wheezing' were defined as follows on the basis of the American Thoracic Society-Division of Lung Disease (ATS-DLD) questionnaire ${ }^{13}$ and a preliminary survey by Shima et $a l^{14}$ The preliminary survey showed that the sensitivity and specificity of the questionnaire used in the present study, for the paediatrician's diagnosis of infantile asthma based on the guidelines by the Japanese Society of Pediatric Allergy and Clinical Immunology, ${ }^{15}$ were $17.9 \%$ and $97.2 \%$, respectively.

Participants with 'asthma': A history of two or more attacks of dyspnoea accompanied by wheezing.

Participants with 'wheezing': A history of two or more episodes of wheezing or whistling in the chest without a history of asthma.

\section{Follow-up survey}

For the follow-up of all 3-year-old children living in the survey areas, a questionnaire survey was performed. The participants were identified every month in 2008-2010 on the basis of the resident registration of the local governments. A questionnaire was mailed to each home of the participants $(n=104477)$ using a method similar to that in the baseline survey. The parents brought the questionnaire with them when their children underwent the health check-up examination for 3-year-old children. Replies were obtained from the parents of 62514 participants $(59.8 \%)$. For participants who moved, questionnaires were mailed to the new addresses.

The questionnaire items were similar to those in the baseline survey for 11/2-year-old children. The definition of 'asthma' was the same as that in the baseline survey. From 1 1/2 to 3 years of age, 43343 participants could be followed up (follow-up rate, $69.1 \%$ ). Participants who did not have 'asthma' at the age of $1 \frac{1}{2} 2$ years and had 
Baseline study for 1.5-year-old

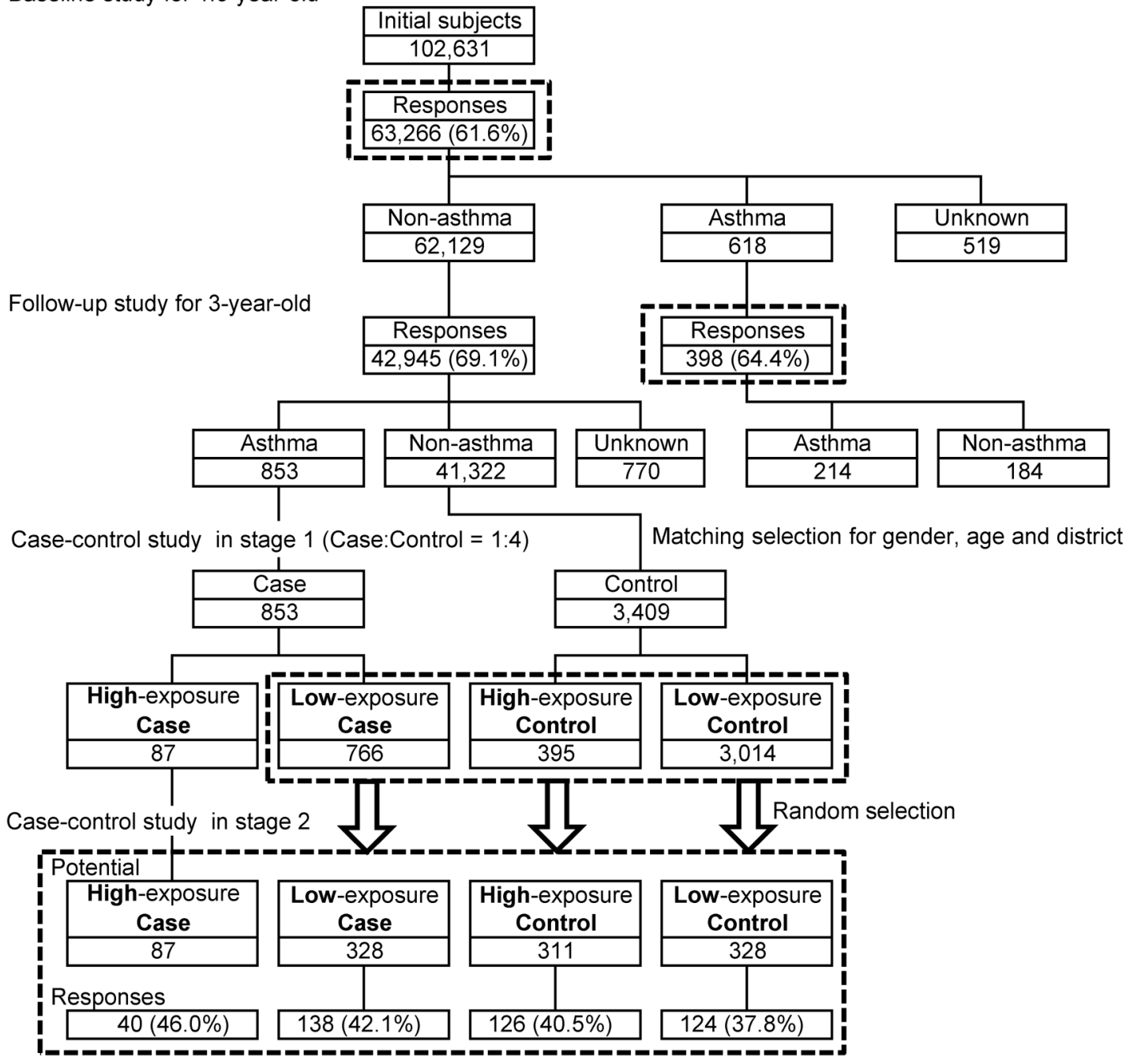

Figure 1 Flow chart of the two-stage nested case-control study design.

'asthma' at the age of 3 years were regarded as cases for a nested case-control study. Participants who had 'asthma' at the ages of both $1 \frac{1}{2}$ and 3 years were defined as patients with persistent asthmatic symptoms.

\section{Two-stage nested case-control study}

A flow chart of the study design is shown in figure 1 . In total, 853 case subjects who developed asthma between $1 \frac{1}{2}$ and 3 years of age were identified. The incidence of asthma during this period was $2.0 \%$. Controls (4 controls per case) who matched the cases in terms of gender, age (months) and area were extracted from 41322 children without asthma at the age of $1 \frac{1}{2}$ years. Since three controls were unavailable, 3409 controls were finally selected for the control group.

Subsequently, 853 cases and 3409 controls were classified into four groups according to the estimated outdoor elemental carbon (EC) concentration at home: high-exposure case and control groups (corresponding to the top $4 \%$ EC concentrations) and low-exposure case and control groups (corresponding to the other concentrations). The high-exposure groups included only 87 cases and 395 controls. Since both disease and exposure were rare in our study, we adopted a two-stage case-control design. ${ }^{16}$ All 87 cases in the high-exposure group are included as participants while participants in the other three groups are selected by random sampling. This method is reported to be efficient, similar to that of a complete survey. ${ }^{17}$

All 87 cases in the high-exposure group were included as participants. From 395 controls in the high-exposure group, 766 cases in the low-exposure group, and 3014 controls in the low-exposure group, 311, 328 and 328, respectively, were randomly selected. Finally, the parents of 1054 participants were asked to consent to an interview, blood examination and mite allergen test (figure 1).

The questions asked in an interview were family, histories of residence, attendance in nursery school/kindergarten, and childhood diseases, period of attacks of asthma, living environment, familial smoking habits, feeding methods, weaning time, vaccinations, house structure, height and weight.

For blood examination, participants visited cooperating medical institutions, and $4 \mathrm{~mL}$ of blood was 
collected and examined for specific IgE concentrations for eight common allergens (Japanese cedar, mite, cat, dog, cockroach, egg white, milk and wheat) using ImmunoCAP (Phadia, Sweden). For children who had undergone these tests during the previous 1-year period, their test data were provided. Children with a specific IgE concentration of $0.70 \mathrm{kU} / \mathrm{L}$ or above for one or more allergens were considered positive.

For the bedding mite allergen test, the parents were asked to rub the upper side of a sheet $(20 \times 30 \mathrm{~cm})$ for $1 \mathrm{~min}$, and researchers classified the allergen level using a Dani Scan (Asahi Food \& Health Care, Ltd, Tokyo, Japan $)^{18}$ into 4 grades: 4 , 'extreme contamination'; 3, 'progressed contamination'; 2, 'slight contamination'; and 1, 'no contamination'. Grades 4 and 3 were regarded as positive for the allergen test, and grades 2 and 1 were regarded as negative.

\section{Exposure assessment}

Nitrogen oxides (NOx) and EC were chosen as indicator air pollutants. In roadside areas, both originate predominantly from automobiles. In the prevalence/persistence study, the estimated outdoor concentrations of NOx and $\mathrm{EC}$ at home during the first $1 \frac{1 / 2}{2}$ years of life were used as parameters for the evaluation of exposure. Changes in residential address were taken into account when estimating exposure, whereas in the case-control study for incidence of asthma the personal exposure levels, estimated by the dispersion model including time-activity pattern at home and nursery school during the first $1 \frac{1}{2}$ years of life and, in addition, taking into account changes in address were used.

To calculate long-term exposure both at a reasonably high spatial resolution and at a feasible computational cost, we developed an outdoor exposure estimation model, which estimates annual average outdoor concentrations of NOx and EC. ${ }^{19}$ The model is composed of two nested plume dispersion-type submodels: super-wide area (1 km grid) and wide area (arbitrary resolution) models. The super-wide area model estimates areaaveraged concentration in the grid cells by using a Gaussian plume dispersion model based on Japanese guidelines. $^{2021}$ The wide area model estimates the concentration at subject points by using a Gaussian plume dispersion model based on the same guidelines. Only road vehicles on heavy-traffic roads that pass through the areas where the study participants reside were considered as emission sources. Model performance was confirmed by field measurements. The square Pearson's correlation coefficients $\left(\mathrm{R}^{2}\right)$ between estimated and measured concentrations in the SORA study were $0.76-$ 0.88 in NOx and 0.59-0.67 in EC. Further details on the models are described elsewhere. ${ }^{19}$

Personal exposure levels of NOx and EC for each participant were calculated as a time-weighted average of the prediction by the developed dispersion model, and the indoor concentration was calculated assuming an infiltration rate from outdoor concentration. The detailed method is provided in online supplementary appendix A. (See the differences between personal exposure levels and outdoor concentrations in online supplementary figure S2 and table S1.)

\section{Statistical analyses}

In the baseline survey, a logistic regression analysis was performed to investigate the associations between the prevalence of asthma and outdoor concentration of NOx or EC adjusted for potential confounding variables, which are known or suspected to be associated with paediatric asthma. The following variables were taken into consideration for analysis as potential confounders: gender, districts, birth season, years of residence, feeding method during the first 3 months of life, familial smoking habits, house structure, heating system, history of pneumonia/bronchitis, empyema and allergic diseases, and parental history of asthma, atopic dermatitis and pollinosis. The ORs and their associated 95\% CIs were calculated. The NOx or EC concentrations were classified as levels 5-1 (top 5\%, 6-25\%, 26-50\%, 51$75 \%$ and $76-100 \%$, respectively). Since the doseresponse relationship may not be linear, we used categorised variables.

In the nested case-control study, a weighted logistic regression model was used to investigate the associations between the incidence of asthma and personal NOx or EC exposure level adjusted for matching factors and potential confounding variables. The ORs are estimated using the inverse probability of sampling weights. ${ }^{16}{ }^{22}$ As potential confounding variables, the results of the interview survey, blood examination and mite allergen test were also added to the analysis. Robust variances were used to test the null hypotheses and to calculate CIs.

The persistence of asthmatic symptoms (between 1/1/2 and 3 years) was also investigated in the follow-up survey. A logistic regression analysis was performed to investigate the associations between the persistence of asthmatic symptoms and outdoor concentration of NOx or EC adjusted for potential confounding variables.

We also adjusted for background concentrations of suspended particulate matter (SPM) and photochemical oxidants $(\mathrm{Ox})$ for $\mathrm{NOx}$ model, nitrogen dioxides $\left(\mathrm{NO}_{2}\right)$ and Ox for EC model in the prevalence, incidence and persistence study. We used individual mean concentrations of SPM, Ox and $\mathrm{NO}_{2}$, collected at the nearest air pollution monitoring stations during the first $1 \frac{1 / 2}{2}$ ears of life. All statistical analyses were performed with SAS V.9.2 (SAS Institute Inc, Cary, North Carolina, USA).

\section{Sensitivity analyses}

We conducted several sensitivity analyses to examine the robustness of our findings on the incidence and persistence of asthma. In the incidence study, we included crude analysis, with adjusting specific IgE test and mite allergen test, with adjusting background air pollution, use of continuous variables for personal exposure levels instead of categorisations, use of distance from heavily 
trafficked roads $(<50 \mathrm{~m}, 50 \mathrm{~m}$ to $<100 \mathrm{~m}, 100 \mathrm{~m}$ or more), and with adjusting birth, the Kaup index, history of attendance in nursery school/kindergarten, birth order, parent with asthma, house structure, heating system, keeping pets (fowl, mammals), familial smoking habits at the age of $1 \frac{1}{2}$ years, feeding method during the first 3 months of life, and vaccines. In the persistence study, we included crude analysis, with adjusting background air pollution, and with adjusting gender, districts, birth season, years of residence, feeding method during the first 3 months of life, familial smoking habits, structure of house, heating system, keeping pets (cats, birds, dogs, hamsters, others).

\section{RESULTS}

\section{Baseline survey}

Descriptive data for the study population are given in table 1. The baseline survey showed a prevalence of asthma of $1.0 \%$ and that of wheezing to be $21.8 \%$. The means $\pm \mathrm{SD}$ of NOx and EC concentrations were 37.7 $\pm 7.8 \mathrm{ppb}$ and $2.85 \pm 0.45 \mu \mathrm{g} / \mathrm{m}^{3}$, respectively. Their five concentration categories (levels 1-5) are shown in table 1 . The top 5\% (level 5) was 50.9-136.8 ppb for NOx and $3.6-7.5 \mu \mathrm{g} / \mathrm{m}^{3}$ for EC. Correlation coefficients between air pollutants (NOx, EC, $\mathrm{NO}_{2}$, SPM and $\mathrm{Ox}$ ) were provided in online supplementary table S2.

The results of logistic regression analyses with the prevalence of asthma and wheezing as the outcome variables are shown in table 2. As for the prevalence of asthma, the OR of level 5 NOx compared with level 1 was 1.20 (95\% CI 0.79 to 1.84 ), and that of level 5 EC compared with level 1 was 1.04 (95\% CI 0.67 to 1.61 ). Both ratios were not statistically significant.

Concerning the prevalence of wheezing, the ORs of levels 2-5 of EC compared with level 1 were 1.08-1.10. The ORs of levels 2-4 were significant. The ORs for levels $2-5$ of NOx compared with level 1 were 1.05-1.08, which were not significant.

The analyses based on continuous variables for NOx and EC concentrations also showed no significant associations with the prevalence of either asthma or wheezing.

\section{Two-stage nested case-control study}

An interview survey was performed in 428 participants $(40.6 \%)$, a bedding mite allergen test in 296 participants $(28.1 \%)$, and blood examination in 181 participants (17.2\%). Descriptive data for a two-stage nested casecontrol study population are provided in online supplementary table S3.

The results of crude, primary and sensitivity analyses of associations between the incidence of asthma from $1 \frac{1}{2}$ to 3 years and personal NOx/EC exposure levels or distance from heavily trafficked roads using a logistic model are shown in table 3 . In the crude analysis, the ORs for level 5 of the estimated personal NOx and EC exposure levels compared with level 1 were 0.75 (95\%
CI 0.27 to 2.07 ) and 1.27 (95\% CI 0.55 to 2.93 ), respectively. With adjusting specific IgE test and mite allergen test, the ORs for level 5 of the estimated personal NOx and EC exposures compared with level 1 were $0.89(95 \%$ CI 0.14 to 5.80 ) and 0.34 (95\% CI 0.06 to 1.91 ), respectively. ORs were not stable, and no statistically positive relationship was observed in any analyses. The factors associated with the incidence of asthma between $1 \frac{1}{2}$ and 3 years of age were a history of bronchiolitis, allergic rhinitis and fever episodes $\geq 5$ times, familial smoking habits and a positive specific $\operatorname{IgE}$ test.

\section{Persistence of asthmatic symptoms}

Of the participants 'with asthmatic symptoms' in the baseline survey, 398 also participated in the follow-up survey. In these participants, logistic analysis was performed with the persistence of asthmatic symptoms (from $1 \frac{1}{2}$ to 3 years) as the outcome variable, and the results of crude, primary and sensitivity analyses are shown in table 4. The OR for level 5 of the estimated outdoor NOx concentration compared with that for level 1 was 6.02 (95\% CI 1.51 to 23.92) in the primary analysis. The OR for level 5 of the estimated outdoor EC concentration was 2.09 (95\% CI 0.61 to 7.14 ). Through the sensitivity analyses, the positive association between outdoor NOx concentration and persistence of asthmatic symptoms remained positive.

The analyses based on continuous variables for NOx and EC concentrations showed no significant associations with the persistence of asthma, although the ORs were larger than 1.

\section{DISCUSSION}

In this study, there was no significant association between exposure to traffic-related air pollution and the development of asthma from $1 \frac{1 / 2}{2}$ to 3 years of age. On the other hand, exposure to traffic-related air pollution was significantly associated with the prevalence of wheezing at the age of $1 \frac{1 / 2}{2}$ years as well as the persistence of asthmatic symptoms (between $1 \frac{1}{2}$ and 3 years of age).

Cohort studies in recent years in which exposure to car exhaust was evaluated using personal exposure levels have shown interesting results. Clark et a $\bar{p}$ assessed children born in British Columbia for the incidence of asthma diagnosis up to 3-4 years of age using outpatient and hospitalisation records. They observed a significantly increased risk of asthma diagnosis with increased utero and first-year exposures. In the BAMSE, a birth cohort survey in Sweden, Gruzieva et $a l^{7}$ followed 4089 children with repeated questionnaires and blood samples at 1,2 , 4,8 and 12 years of age. They evaluated personal exposure in terms of particulate matter less than $10 \mu \mathrm{m}$ in aerodynamic diameter $\left(\mathrm{PM}_{10}\right)$ and NOx from traffic using residential, daycare, and school addresses, timeactivity patterns, emission databases, and dispersion models. There was an association between exposure to air pollution during the first year of life and the 
Table 1 Descriptive data at $1 \frac{1}{2}$ years of age for the baseline survey, the nested case-control study and persistence study

\begin{tabular}{|c|c|c|c|c|c|c|c|c|}
\hline & \multirow{2}{*}{\multicolumn{2}{|c|}{ Baseline study }} & \multicolumn{4}{|c|}{ Nested case-control study } & \multirow{2}{*}{\multicolumn{2}{|c|}{$\begin{array}{l}\text { Persistence } \\
\text { study }\end{array}$}} \\
\hline & & & \multicolumn{2}{|c|}{ Control } & \multicolumn{2}{|c|}{ Case } & & \\
\hline & $\overline{\mathbf{N}}$ & Per cent & $\overline{\mathbf{N}}$ & Per cent & $\overline{\mathbf{N}}$ & Per cent & $\overline{\mathbf{N}}$ & Per cent \\
\hline Participants & 63266 & 100.0 & 3409 & 100.0 & 853 & 100.0 & 398 & 100.0 \\
\hline \multicolumn{9}{|l|}{ Gender } \\
\hline Boys & 32627 & 51.6 & 2132 & 62.5 & 533 & 62.5 & 272 & 68.3 \\
\hline Girls & 30554 & 48.3 & 1277 & 37.5 & 320 & 37.5 & 126 & 31.7 \\
\hline \multicolumn{9}{|l|}{ Wheezing at $1 \frac{1}{2}$ years } \\
\hline No & 49475 & 78.2 & 2659 & 78.0 & 367 & 43.0 & - & \\
\hline Yes & 13791 & 21.8 & 750 & 22.0 & 486 & 57.0 & - & \\
\hline \multicolumn{9}{|l|}{ Asthma at $1 \frac{1}{2}$ years } \\
\hline No & 62648 & 99.0 & 3409 & 100.0 & 853 & 100.0 & - & \\
\hline Yes & 618 & 1.0 & - & & - & & 398 & 100.0 \\
\hline \multicolumn{9}{|c|}{ Feeding method during the first 3 months of life } \\
\hline Bottle feeding & 5716 & 9.0 & 326 & 9.6 & 72 & 8.4 & 44 & 11.1 \\
\hline Mixture & 21411 & 33.8 & 1143 & 33.5 & 292 & 34.2 & 128 & 32.2 \\
\hline Breast milk & 35875 & 56.7 & 1935 & 56.8 & 485 & 56.9 & 225 & 56.7 \\
\hline \multicolumn{9}{|l|}{ Pets at $1 \frac{1}{2}$ years } \\
\hline Pets (presently) & 9305 & 14.7 & 465 & 13.6 & 154 & 18.1 & 64 & 16.1 \\
\hline Pets (previously) & 2512 & 4.0 & 112 & 3.3 & 43 & 5.0 & 23 & 5.8 \\
\hline Never & 50787 & 80.3 & 2817 & 82.6 & 651 & 76.3 & 310 & 78.1 \\
\hline \multicolumn{9}{|c|}{ Familial smoking habits at $1 \frac{1}{2}$ years } \\
\hline Mother smokes & 5591 & 8.8 & 258 & 7.6 & 96 & 11.3 & 51 & 12.9 \\
\hline Others smoke & 13637 & 21.6 & 701 & 20.6 & 193 & 22.6 & 82 & 20.8 \\
\hline No smokes & 43469 & 68.7 & 2430 & 71.3 & 554 & 64.9 & 262 & 66.3 \\
\hline \multicolumn{9}{|l|}{ History of allergic diseases* } \\
\hline Yes & 10975 & 17.3 & 573 & 16.8 & 268 & 31.4 & 135 & 34.5 \\
\hline No & 48095 & 76.0 & 2640 & 77.4 & 547 & 64.1 & 256 & 65.5 \\
\hline \multicolumn{9}{|c|}{ Parental history of allergic diseases } \\
\hline Yes & 37583 & 59.4 & 2074 & 60.8 & 653 & 76.6 & 319 & 81.8 \\
\hline No & 23096 & 36.5 & 1215 & 35.6 & 175 & 20.5 & 71 & 18.2 \\
\hline \multicolumn{9}{|c|}{ Outdoor concentration of NOx at $1 \frac{1}{2}$ years $(\mathrm{ppb}) \dagger$} \\
\hline 50.9-136.8 (level 5) & 3186 & 5.0 & 205 & 6.0 & 41 & 4.8 & 29 & 7.3 \\
\hline 42.1-50.8 (level 4) & 12658 & 20.0 & 647 & 19.0 & 181 & 21.2 & 108 & 27.1 \\
\hline 37.2-42.0 (level 3) & 15856 & 25.1 & 874 & 25.6 & 214 & 25.1 & 101 & 25.4 \\
\hline 32.6-37.1 (level 2) & 15801 & 25.0 & 820 & 24.1 & 197 & 23.1 & 89 & 22.4 \\
\hline 13.9-32.5 (level 1) & 15765 & 25.0 & 863 & 25.3 & 220 & 25.8 & 71 & 17.8 \\
\hline \multicolumn{9}{|c|}{ Outdoor concentration of $E C$ at $1 \frac{1}{2}$ years $\left(\mu \mathrm{g} / \mathrm{m}^{3}\right) \ddagger$} \\
\hline 3.6-7.5 (level 5) & 3958 & 6.3 & 222 & 6.5 & 48 & 5.6 & 26 & 6.5 \\
\hline 3.1-3.5 (level 4) & 16389 & 25.9 & 839 & 24.6 & 232 & 27.2 & 90 & 22.6 \\
\hline 2.8-3.0 (level 3) & 15430 & 24.4 & 839 & 24.6 & 204 & 23.9 & 82 & 20.6 \\
\hline 2.5-2.7 (level 2) & 15787 & 25.0 & 893 & 26.2 & 217 & 25.4 & 107 & 26.9 \\
\hline 1.3-2.4 (level 1) & 11702 & 18.5 & 616 & 18.1 & 152 & 17.8 & 93 & 23.4 \\
\hline \multicolumn{9}{|c|}{ Distance from traffic, main road at $1 \frac{1}{2}$ years } \\
\hline$<50 \mathrm{~m}$ & 2394 & 3.8 & 138 & 4.0 & 29 & 3.4 & 17 & 4.3 \\
\hline $50 \mathrm{~m}$ to $<100 \mathrm{~m}$ & 2700 & 4.3 & 144 & 4.2 & 37 & 4.3 & 21 & 5.3 \\
\hline $100 \mathrm{~m}$ or more & 58172 & 91.9 & 3127 & 91.7 & 787 & 92.3 & 360 & 90.5 \\
\hline Birth season & & & & & & & & \\
\hline December-February & 15488 & 24.5 & 976 & 28.6 & 244 & 28.6 & 88 & 22.1 \\
\hline March-May & 18338 & 29.0 & 920 & 27.0 & 230 & 27.0 & 129 & 32.4 \\
\hline June-August & 18616 & 29.4 & 929 & 27.3 & 233 & 27.3 & 116 & 29.1 \\
\hline September-November & 10824 & 17.1 & 584 & 17.1 & 146 & 17.1 & 65 & 16.3 \\
\hline Years of residence & & & & & & & & \\
\hline Below 1 year & 9178 & 14.5 & 484 & 14.2 & 111 & 13.0 & 49 & 12.3 \\
\hline Over 1 year & 7161 & 11.3 & 383 & 11.2 & 77 & 9.0 & 30 & 7.5 \\
\hline The same since birth & 46672 & 73.8 & 2539 & 74.5 & 663 & 77.7 & 317 & 79.6 \\
\hline Structure of house & & & & & & & & \\
\hline Wooden house & 16381 & 25.9 & 987 & 29.0 & 250 & 29.3 & 125 & 31.4 \\
\hline
\end{tabular}


Table 1 Continued

\begin{tabular}{|c|c|c|c|c|c|c|c|c|}
\hline & \multirow{2}{*}{\multicolumn{2}{|c|}{ Baseline study }} & \multicolumn{4}{|c|}{ Nested case-control study } & \multirow{2}{*}{\multicolumn{2}{|c|}{$\begin{array}{l}\text { Persistence } \\
\text { study }\end{array}$}} \\
\hline & & & \multicolumn{2}{|c|}{ Control } & \multicolumn{2}{|c|}{ Case } & & \\
\hline & $\mathbf{N}$ & Per cent & $\mathbf{N}$ & Per cent & $\mathbf{N}$ & Per cent & $\mathbf{N}$ & Per cent \\
\hline Steel frame building & 46113 & 72.9 & 2392 & 70.2 & 595 & 69.8 & 273 & 68.6 \\
\hline \multicolumn{9}{|l|}{ History of pneumonia } \\
\hline Yes & 2833 & 4.5 & 137 & 4.0 & 100 & 11.7 & 87 & 21.9 \\
\hline No & 60433 & 95.5 & 3272 & 96.0 & 753 & 88.3 & 311 & 78.1 \\
\hline \multicolumn{9}{|l|}{ History of empyema } \\
\hline Yes & 599 & 0.9 & 32 & 0.9 & 16 & 1.9 & 7 & 1.8 \\
\hline No & 62667 & 99.1 & 3377 & 99.1 & 837 & 98.1 & 391 & 98.2 \\
\hline \multicolumn{9}{|l|}{ Heating system } \\
\hline Without ventilation & 19533 & 30.9 & 1081 & 31.7 & 292 & 34.2 & 133 & 33.4 \\
\hline With ventilation & 2512 & 4.0 & 119 & 3.5 & 34 & 4.0 & 25 & 6.3 \\
\hline No heating system & 40588 & 64.2 & 2184 & 64.1 & 522 & 61.2 & 239 & 60.1 \\
\hline \multicolumn{9}{|l|}{ Districts } \\
\hline Chiba & 3213 & 5.1 & 216 & 6.3 & 54 & 6.3 & 23 & 5.8 \\
\hline Itabashi & 4303 & 6.8 & 248 & 7.3 & 62 & 7.3 & 36 & 9.0 \\
\hline Suginami & 3476 & 5.5 & 260 & 7.6 & 65 & 7.6 & 34 & 8.5 \\
\hline Setagaya & 5402 & 8.5 & 248 & 7.3 & 62 & 7.3 & 26 & 6.5 \\
\hline Kawasaki & 9930 & 15.7 & 688 & 20.2 & 172 & 20.2 & 62 & 15.6 \\
\hline Yokohama & 13250 & 20.9 & 772 & 22.6 & 193 & 22.6 & 97 & 24.4 \\
\hline Nagoya & 9493 & 15.0 & 388 & 11.4 & 97 & 11.4 & 52 & 13.1 \\
\hline Osaka & 9260 & 14.6 & 397 & 11.6 & 100 & 11.7 & 48 & 12.1 \\
\hline Kobe & 4939 & 7.8 & 192 & 5.6 & 48 & 5.6 & 20 & 5.0 \\
\hline Chiba & 3213 & 5.1 & 216 & 6.3 & 54 & 6.3 & 23 & 5.8 \\
\hline
\end{tabular}

Table 2 Association between prevalence of asthma and wheezing at the age of 11/2 years and outdoor NOx or EC concentrations in the baseline survey using a logistic model, adjusted for potential confounding variables $(n=57682)^{*} \dagger$

\begin{tabular}{|c|c|c|}
\hline & \multicolumn{2}{|l|}{ Outcomes } \\
\hline & Prevalence of asthma & Prevalence of wheezing \\
\hline \multicolumn{3}{|l|}{ Outdoor NOx concentration } \\
\hline Level 5 (50.9-136.8 ppb) & $1.20(0.79$ to 1.84$)$ & $1.08(0.97$ to 1.21$)$ \\
\hline Level 4 (42.1-50.8 ppb) & $1.08(0.80$ to 1.45$)$ & 1.05 (0.98 to 1.14$)$ \\
\hline Level 3 (37.2-42.0 ppb) & $0.92(0.70$ to 1.22$)$ & 1.05 (0.98 to 1.12$)$ \\
\hline Level 2 (32.6-37.1 ppb) & $1.18(0.91$ to 1.52$)$ & 1.06 (0.99 to 1.13$)$ \\
\hline Level 1 (13.9-32.5 ppb) & 1.00 & 1.00 \\
\hline \multicolumn{3}{|l|}{ Outdoor EC concentration } \\
\hline Level $5\left(3.6-7.5 \mu \mathrm{g} / \mathrm{m}^{3}\right)$ & $1.04(0.79$ to 1.84$)$ & $1.08(0.97$ to 1.21$)$ \\
\hline Level $4\left(3.1-3.5 \mu \mathrm{g} / \mathrm{m}^{3}\right)$ & $1.02(0.80$ to 1.45$)$ & 1.10 (1.01 to 1.19$)$ \\
\hline Level $3\left(2.8-3.0 \mu \mathrm{g} / \mathrm{m}^{3}\right)$ & 1.01 (0.70 to 1.22$)$ & $1.10(1.02$ to 1.18$)$ \\
\hline Level $2\left(2.5-2.7 \mu \mathrm{g} / \mathrm{m}^{3}\right)$ & $0.93(0.91$ to 1.52$)$ & $1.10(1.03$ to 1.18$)$ \\
\hline Level $1\left(1.3-2.4 \mu \mathrm{g} / \mathrm{m}^{3}\right)$ & 1.00 & 1.00 \\
\hline \multicolumn{3}{|c|}{ Continuous variables for outdoor concentration } \\
\hline NOx (per 1 ppb) & $1.00(0.99$ to 1.01$)$ & $1.00(1.00$ to 1.01$)$ \\
\hline $\mathrm{EC}\left(\right.$ per $\left.0.1 \mu \mathrm{g} / \mathrm{m}^{3}\right)$ & $1.01(0.98$ to 1.03$)$ & $1.01(1.00$ to 1.01$)$ \\
\hline \multicolumn{3}{|c|}{$\begin{array}{l}\text { *Data are presented as OR ( } 95 \% \text { Cls). } \\
\text { †Potential confounding variables include gender, districts, birth season, years of residence, feeding method during the first } 3 \text { months of life, } \\
\text { familial smoking habits, structure of house, heating system, keeping pets (cats, birds, dogs, hamsters, others), background concentration of } \\
\text { air pollutants, history of disease before the age of } 11 \frac{1}{2} \text { years, such as bronchitis/pneumonia, empyema and allergic disease; and parental } \\
\text { history of allergic diseases, such as asthma, atopic dermatitis and pollinosis. } \\
\text { EC, elemental carbon; NOx, nitrogen oxides. }\end{array}$} \\
\hline
\end{tabular}


Table 3 Crude, primary and sensitivity analyses of associations between incidence of asthma from $1 \frac{1}{2}$ to 3 years and personal NOx/EC exposure levels ${ }^{*}$ or distance from heavily trafficked roads in the two-stage nested case-control study, adjusted for potential confounding variables $\dagger$

\begin{tabular}{|c|c|c|}
\hline & $\begin{array}{l}\text { NOx } \\
\text { OR }(95 \% \mathrm{Cl})\end{array}$ & $\begin{array}{l}\text { EC } \\
\text { OR }(95 \% \mathrm{Cl})\end{array}$ \\
\hline \multicolumn{3}{|c|}{ Crude analysis $(n=428)$} \\
\hline Level 5 & $0.75(0.27$ to 2.07$)$ & $1.27(0.55$ to 2.93$)$ \\
\hline Level 4 & 0.39 (0.19 to 0.83$)$ & 0.52 (0.27 to 1.02$)$ \\
\hline Level 3 & $0.78(0.43$ to 1.41$)$ & 0.77 (0.41 to 1.45$)$ \\
\hline Level 2 & $0.54(0.31$ to 0.95$)$ & 0.57 (0.32 to 1.02$)$ \\
\hline Level 1 & 1.00 & 1.00 \\
\hline \multicolumn{3}{|c|}{ Sensitivity -with adjusting background air pollution $(n=428)$} \\
\hline Level 5 & $0.73(0.26$ to 2.05$)$ & $1.03(0.41$ to 2.55$)$ \\
\hline Level 4 & 0.39 (0.18 to 0.82$)$ & $0.43(0.21$ to 0.90$)$ \\
\hline Level 3 & $0.76(0.76$ to 0.52$)$ & 0.66 (0.34 to 1.29$)$ \\
\hline Level 2 & $0.52(0.29$ to 0.93$)$ & 0.51 (0.28 to 0.94$)$ \\
\hline Level 1 & 1.00 & 1.00 \\
\hline \multicolumn{3}{|c|}{ Sensitivity-with adjusting specific IgE test and mite allergen test $(n=155)$} \\
\hline Level 5 & $0.89(0.14$ to 5.80$)$ & $0.34(0.06$ to 1.91$)$ \\
\hline Level 4 & $0.86(0.26$ to 2.82$)$ & 0.20 (0.05 to 0.83$)$ \\
\hline Level 3 & $0.80(0.25$ to 2.55$)$ & 0.70 (0.18 to 2.72$)$ \\
\hline Level 2 & $1.38(0.45$ to 4.30$)$ & 0.30 (0.09 to 1.06$)$ \\
\hline Level 1 & 1.00 & 1.00 \\
\hline
\end{tabular}

Sensitivity -with adjusting birth, the Kaup index, history of attendance in nursery school/kindergarten, birth order, parent with asthma, house structure, heating system, keeping pets (fowl, mammals), familial smoking habits at the age of $1 \frac{1}{2}$ years,

feeding method during the first 3 months of life, and vaccines $(n=416)$

$\begin{array}{ll}\text { Level } 5 & 0.53(0.15 \text { to } 1.84) \\ \text { Level } 4 & 0.27(0.11 \text { to } 0.68) \\ \text { Level } 3 & 0.64(0.34 \text { to } 1.18) \\ \text { Level } 2 & 0.47(0.25 \text { to } 0.90) \\ \text { Level } 1 & 1.00\end{array}$

0.84 (0.31 to 2.32$)$

0.30 (0.14 to 0.67$)$

$0.47(0.23$ to 0.95$)$

0.35 (0.18 to 0.67$)$

Level 1

1.00

1.00

Primary analysis - with adjusting potential confounding variables ${ }^{*} \dagger(n=150)$

Level 5

4.21 ( 0.39 to 45.73$)$

$0.12(0.01$ to 1.67$)$

Level 4

$0.91(0.14$ to 5.86$)$

$0.03(0.00$ to 0.40$)$

Level 3

$1.88(0.31$ to 11.24$)$

$0.13(0.02$ to 0.90$)$

Level 2

$3.30(0.57$ to 18.92$)$

0.05 (0.00 to 0.69$)$

Level 1

1.00

1.00

Continuous variables for personal exposure levels $(n=416)$

NOx (per $1 \mathrm{ppb}$ )

EC $\left(\right.$ per $\left.0.1 \mu \mathrm{g} / \mathrm{m}^{3}\right)$

0.97 (0.95 to 1.00$)$

$-$

$$
\text { OR }(95 \% \mathrm{CI})
$$

$0.93(0.85$ to 1.01$)$

Distance from heavily trafficked roads $(n=415)$

$<50 \mathrm{~m}$

$1.30(0.42$ to 3.99$)$

$50 \mathrm{~m}$ to $<100 \mathrm{~m}$

1.63 (0.57 to 4.69$)$

$100 \mathrm{~m}$ or more

1.00

*Personal NOx exposure levels of levels $1-5$ are 31.6-48.0, 48.1-54.0, 54.1-61.3, 61.4-72.8, and 72.9-96.4 ppb, respectively. Personal EC exposure levels of levels $1-5$ are $1.2-1.8,1.9-2.0,2.1-2.2,2.3-2.6$, and $2.7-3.4 \mu \mathrm{g} / \mathrm{m}^{3}$, respectively.

†Potential confounding variables include gender, year of birth, the Kaup index, history of attendance in nursery school/kindergarten, birth order, parent with asthma, house structure, heating system, keeping pets (fowl, mammals), familial smoking habits at the age of $1 \frac{1}{2}$ years, feeding method during the first 3 months of life, vaccines (influenza vaccine for 2-year-old children), background concentration of air pollutants, blood test, bedding mite allergen test, and history of disease before the age of $1 \frac{1}{2}$ years, such as wheezing, pneumonia/bronchitis, atopic dermatitis, allergic rhinitis, food allergy, and number of fever episodes.

EC, elemental carbon; NOx, nitrogen oxides.

incidence of asthma from 8 to 12 years of age, but not from 1 to 8 years.

Gehring et $a l^{8}$ performed analysis in 3863 participants in the PIAMA study as a birth cohort survey in the Netherlands. They estimated personal exposure to $\mathrm{NO}_{2}$, $\mathrm{PM}_{2.5}$ and soot at the birth address using LUR models, and performed an annual questionnaire until the age of
8 years. $\mathrm{PM}_{2.5}, \mathrm{NO}_{2}$ and soot at the birth address were significantly associated with an increased risk of incidence of asthma past 12 months at the age of 8 years, but not from 1 to 7 years. Ranzi et a $t^{9}$ conducted direct interviews of 672 mothers at birth and at 6 months, 15 months, 4 years and 7 years in a birth cohort (Rome, Italy). They did not find a clear link between exposure 
Table 4 Crude, primary and sensitivity analyses of associations between persistence of asthmatic symptoms from $1 \frac{11 / 2}{2}$ to 3 years and outdoor NOx or EC concentrations* or distance from heavily trafficked roads using a logistic model, adjusted for potential confounding variablest

\begin{tabular}{|c|c|c|}
\hline & $\begin{array}{l}\text { NOx } \\
\text { OR }(95 \% \mathrm{Cl})\end{array}$ & $\begin{array}{l}\text { EC } \\
\text { OR }(95 \% \mathrm{Cl})\end{array}$ \\
\hline \multicolumn{3}{|l|}{ Crude analysis $(n=398)$} \\
\hline Level 5 & $3.32(1.12$ to 9.84$)$ & $1.40(0.54$ to 3.61$)$ \\
\hline Level 4 & $1.08(0.60$ to 1.94$)$ & $0.91(0.51$ to 1.61$)$ \\
\hline Level 3 & 1.44 (0.82 to 2.52$)$ & $0.72(0.42$ to 1.24$)$ \\
\hline Level 2 & 1.44 (0.82 to 2.52$)$ & $0.79(0.42$ to 1.50$)$ \\
\hline \multicolumn{3}{|l|}{ Level 1} \\
\hline \multicolumn{3}{|c|}{ Sensitivity —with adjusting for background air pollution $(n=398)$} \\
\hline Level 5 & $3.12(1.04$ to 9.37$)$ & $1.26(0.46$ to 3.42$)$ \\
\hline Level 4 & 1.06 (0.58 to 1.93$)$ & $0.82(0.43$ to 1.56$)$ \\
\hline Level 3 & 1.42 (0.80 to 2.52$)$ & $0.66(0.37$ to 1.20$)$ \\
\hline Level 2 & 1.49 (0.84 to 2.66$)$ & $0.75(0.39$ to 1.44$)$ \\
\hline Level 1 & 1.00 & 1.00 \\
\hline \multicolumn{3}{|c|}{$\begin{array}{l}\text { Sensitivity-with adjusting gender, districts, birth season, years of residence, feeding method during the first } 3 \text { months of life, } \\
\text { familial smoking habits, structure of house, heating system, keeping pets (cats, birds, dogs, hamsters, others) ( } n=392)\end{array}$} \\
\hline Level 5 & $6.14(1.66$ to 22.77$)$ & $1.88(0.63$ to 5.61$)$ \\
\hline Level 4 & $1.06(0.49$ to 2.31$)$ & $0.96(0.48$ to 1.94$)$ \\
\hline Level 3 & 1.71 (0.84 to 3.50$)$ & $0.73(0.38$ to 1.38$)$ \\
\hline Level 2 & $1.61(0.82$ to 3.17$)$ & 0.75 (0.36 to 1.52$)$ \\
\hline Level 1 & 1.00 & 1.00 \\
\hline \multicolumn{3}{|c|}{ Primary analysis - with adjusting potential confounding variablest $(n=385)$} \\
\hline Level 5 & $6.02(1.51$ to 23.92$)$ & $2.09(0.61$ to 7.14$)$ \\
\hline Level 4 & 0.91 (0.40 to 2.09$)$ & $0.89(0.38$ to 2.11$)$ \\
\hline Level 3 & 1.56 (0.72 to 3.38$)$ & $0.67(0.32$ to 1.39$)$ \\
\hline Level 2 & 1.44 (0.71 to 2.93$)$ & $0.72(0.33$ to 1.56$)$ \\
\hline Level 1 & 1.00 & 1.00 \\
\hline \multicolumn{3}{|c|}{ Continuous variables for outdoor concentrations $(n=385)$} \\
\hline NOx (per 1 ppb) & $1.02(0.99$ to 1.06$)$ & - \\
\hline $\mathrm{EC}\left(\right.$ per $\left.0.1 \mu \mathrm{g} / \mathrm{m}^{3}\right)$ & - & $1.06(0.99$ to 1.14$)$ \\
\hline \multicolumn{3}{|c|}{$\begin{array}{l}\text { *Outdoor NOx concentrations of levels } 1-5 \text { are } 13.9-32.5,32.6-37.1,37.2-42.0,42.1-50.8 \text { and } 50.9-136.8 \mathrm{ppb} \text {, respectively. Outdoor EC } \\
\text { concentrations of levels } 1-5 \text { are } 1.3-2.4,2.5-2.7,2.8-3.0,3.1-3.5 \text { and } 3.6-7.5 \mu \mathrm{g} / \mathrm{m}^{3} \text {, respectively. } \\
\text { †Potential confounding variables include gender, districts, birth season, years of residence, feeding method during the first } 3 \text { months of life, } \\
\text { familial smoking habits, structure of house, heating system, keeping pets (cats, birds, dogs, hamsters, others), background concentration of } \\
\text { air pollutants, history of disease before the age of } 11 / 2 \text { years, such as bronchitis/pneumonia, empyema and allergic disease; and parental } \\
\text { history of allergic diseases, such as asthma, atopic dermatitis and pollinosis. } \\
\text { EC, elemental carbon; NOx, nitrogen oxides. }\end{array}$} \\
\hline
\end{tabular}

to traffic-related air pollution and respiratory disorders in children during their first 7 years of life, including the incidence of asthma. Only weak associations emerged that seem to increase with age. Lindgren et $a l^{10}$ investigated a birth cohort in Sweden, consisting of 7898 children. They reported that traffic-related exposure was not associated with the incidence of asthma medication or diagnoses of asthma in children aged 0-6 years. Authors said this might be related to relative (low levels of) traffic pollution in the area. In a cohort study in Japan, which was a part of the SORA project, Yamazaki $e t a l^{23}$ performed an annual questionnaire survey for 4 years to follow 10069 first-year to third-year elementary school students (aged 6-9 years). Personal exposures to NOx and EC were estimated using a method similar to that in our study with consideration being given to the exposure levels at school and home. An association between exposure to EC and the incidence of asthma was observed. A cohort study in
Norway had a finding similar to that in our SORA project. A statistically negative association between $\mathrm{NO}_{2}$ and early onset asthma (children <4 years of age) was observed. However, the associations for late asthma onset ( $>4$ years age) were positive but not statistically significant. $^{24}$

The results of the aforementioned seven studies, ${ }^{5}$ 7-10 2324 together with those of our study, provide evidence for an association between exposure to traffic-related air pollution and asthma development from about 3 to 12 years of age, but only limited evidence for such an association during the preschool period. This may have been because the development of asthma during the preschool period is markedly affected by factors such as own and parental history of allergic diseases in addition to environmental factors. ${ }^{25-27}$

Concerning wheezing, the results of our study as well as those of the study by Gehring et $a l^{8}$ and Ranzi et $a l^{9}$ showed a significant association between wheezing 
during the preschool period and the traffic-related air pollutant concentrations. In addition, the statistically significant association between the persistence of asthmatic symptoms and exposure to NOx in our study suggested that exposed children may be at a higher risk for the persistence of asthmatic symptoms. To the best of our knowledge, this study is the first to evaluate the association between air pollution and the persistence of childhood asthma.

There are two strengths in this study. First, as a large-scale population-based cohort study, the prevalence and incidence of asthma during the preschool period could be accurately evaluated. In this study, the prevalence of asthma was $1.0 \%$ at the age of $1 \frac{1}{2}$ years and $2.6 \%$ at the age of 3 years, and the incidence of asthma between $1 \frac{1}{2}$ and 3 years of age was $2.0 \%$. A survey by the Ministry of the Environment Government of Japan using the simplified ATS-DLD questionnaire showed a prevalence of asthma of $2.85 \%$ in 3-year-old children in fiscal year 2009. ${ }^{28} 29$ This prevalence was similar to that in this study. Second, exposure to traffic-related air pollution was estimated with NOx and EC as parameters using an outdoor concentration estimation model. NOx and EC are components to which automobile exhaust contributes greatly, and are even more specific to automobile exhaust than $\mathrm{PM}_{2.5}{ }^{19}$ The evaluation of the validity of estimated values using the outdoor concentration model by comparing them with measured values in the cohort survey in schoolchildren in the SORA project showed good correlation of the measured values compared with the previous studies. The square Pearson's correlation coefficients $\left(R^{2}\right)$ between estimated and measured concentrations in this study were $0.76-0.88$ in NOx and 0.59-0.67 in EC. ${ }^{19}$ The $\mathrm{R}^{2}$ of $\mathrm{NO}_{2}$ in the studies conducted in Sweden ${ }^{10}$ and Norway $^{24}$ were 0.6 and 0.58, respectively. In this study, we did not get information about the activity time for the participants in the baseline and follow-up surveys, and the estimated outdoor concentrations of NOx and EC were used for analysis. In the case-control study, the personal exposure level was estimated using a time-weighted model based on the activity time obtained by an interview.

On the other hand, our study has some limitations. First, the evaluation of the incidence of asthma was defined using a questionnaire. However, this questionnaire was based on the ATS-DLD questionnaire and adequately validated. ${ }^{13}$ In the nested case-control study, we also asked about the treatment for asthma. In addition, to support the evaluation of the incidence of asthma using a questionnaire, participants' predisposition to allergy was evaluated by measuring the specific IgE concentrations for common allergens using blood samples.

Second, there was an inherent difficulty of evaluating asthma at the age of $1 \frac{1}{2}$ years of age. In a preliminary study, the validity of our assessment of asthmatic symptoms in 1/2-year-old children using a questionnaire was evaluated. The specificity of the diagnosis of infantile asthma made by specialists based on the guidelines by the Japanese Society of Pediatric Allergy and Clinical Immunology ${ }^{15}$ was very high $(97.2 \%) .{ }^{14}$ On the other hand, the fact that the sensitivity was $17.9 \%$ implied that our study observed more distinct asthma than previous epidemiological studies. It is considered that low sensitivity might have caused difficulties in exploring the air pollution and asthma association. In addition, recent exposure levels in Japan may have been too low to reveal positive associations with the incidence of such distinct asthma.

Third, there was the possibility of selection bias since the consent rate was about $60 \%$ in both the baseline and the follow-up surveys, and the percentages of the participants who underwent the interview survey and blood examination were also low (40.6 and 17.2\%, respectively) in the nested case-control study. Given the fact that those who participated in the interview survey are more concerned about the cause of asthma, the selection of the group might have biased against an association between air pollution and new onset asthma in the nested case-control study.

Fourth, the unstable result of the incidence study reflects lack of power. To make up for the shortcomings of power, we conducted the additional analyses of associations between the incidence of asthma from $1 \frac{1 / 2}{2}$ to 3 years and outdoor NOx or EC concentrations using a follow-up study sample. The results are shown in online supplementary table $\mathrm{S} 4 \quad(\mathrm{n}=39539)$. The associations were also negative.

In conclusion, no statistically significant association was observed between traffic-related air pollution and the incidence of asthma during the first 3 years of life, after adjustment for factors such as allergic predisposition and a history of respiratory diseases, whereas, the persistence of asthmatic symptoms (between $1 \frac{1 / 2}{2}$ and 3 years) was significantly associated with outdoor concentration of NOx. Traffic-related air pollution may be an important factor of asthma persistence.

\section{Author affiliations}

${ }^{1}$ Department of Public Health, Hyogo College of Medicine, Nishinomiya, Japan ${ }^{2}$ Center for Environmental Information Science, Tokyo, Japan

${ }^{3}$ Department of Biostatistics, Kyoto University School of Public Health, Kyoto, Japan

${ }^{4}$ Department of Education for Childcare, Tokyo Kasei University, Tokyo, Japan ${ }^{5}$ Department of Pediatrics, Graduate School of Medicine, Chiba University, Chiba, Japan

${ }^{6}$ National Institute for Environmental Studies, Tsukuba, Japan ${ }^{7}$ National Hospital Organization Fukuoka Hospital, Fukuoka, Japan ${ }^{8}$ Center Administration Division, Center for Clinical Research, Kobe University Hospital, Kobe, Japan

Acknowledgements The authors thank the external review committee: Tominaga S (chair; Aichi Cancer Center, Japan), Akiba S (Kagoshima University, Japan), Fukuchi Y (Juntendo University, Japan), Kasahara M (Chubu University, Japan), Ota K (Teikyo University, Japan), Morikawa A (Gunma University, Japan), Shirai M (Waseda University, Japan), Yanagisawa Y (the University of Tokyo, Japan), and Yoshimura I (Tokyo University of Science, Japan). They also thank members of the Environmental Health Affairs Office in the Ministry of the Environment Government of Japan (who worked as coordinating officers) and the Center for Environmental Information 
Science, Tokyo, Japan (a data centre for this study) (see online supplementary Appendix B).

Contributors TS, TI, YK, HN, TOh, MO and MS contributed in the conception and design of the study. $\mathrm{HH}, \mathrm{TI}, \mathrm{YK}, \mathrm{HO}$ and MS collected information about children. HH, HN, TOh and MS provided information for exposure assessment. HH, TS, TOm, SY and MS performed statistical analyses. HH and MS drafted the manuscript. TS and MO performed a critical revision of the manuscript. All authors read and approved the final manuscript.

Funding This study was funded by the Ministry of the Environment Government of Japan.

Disclaimer The views expressed in this article are those of the authors and do not necessarily reflect those of the Ministry of the Environment Government of Japan.

Competing interests None declared.

Patient consent Parental/guardian consent obtained.

Ethics approval This study protocol was reviewed and approved by the ethics committee of the Ministry of the Environment Government of Japan.

Provenance and peer review Not commissioned; externally peer reviewed.

Data sharing statement No additional data are available.

Open Access This is an Open Access article distributed in accordance with the Creative Commons Attribution Non Commercial (CC BY-NC 4.0) license, which permits others to distribute, remix, adapt, build upon this work noncommercially, and license their derivative works on different terms, provided the original work is properly cited and the use is non-commercial. See: http:// creativecommons.org/licenses/by-nc/4.0/

\section{REFERENCES}

1. HEI Panel on the Health Effects of Traffic-Related Air Pollution Traffic-related air pollution: a critical review of the literature on emissions, exposure, and health effects 2010. http://pubs. healtheffects.org/getfile.php?u=553 (accessed 10 Aug 2015)

2. Shima M, Nitta $Y$, Adachi M. Traffic-related air pollution and respiratory symptoms in children living along trunk roads in Chiba Prefecture, Japan. J Epidemiol 2003;13:108-19.

3. McConnell R, Islam T, Shankardass K, et al. Childhood incident asthma and traffic-related air pollution at home and school. Environ Health Perspect 2010;118:1021-6.

4. Gonzalez-Barcala FJ, Pertega S, Garnelo L, et al. Truck traffic related air pollution associated with asthma symptoms in young boys: a cross-sectional study. Public Health 2013;127:275-81.

5. Clark NA, Demers PA, Karr CJ, et al. Effect of early life exposure to air pollution on development of childhood asthma. Environ Health Perspect 2010;118:284-90.

6. Morgenstern V, Zutavern A, Cyrys J, et al. Atopic diseases, allergic sensitization, and exposure to traffic-related air pollution in children. Am J Respir Crit Care Med 2008;177:1331-7.

7. Gruzieva O, Bergström A, Hulchiy $O$, et al. Exposure to air pollution from traffic and childhood asthma until 12 years of age. Epidemiology 2013;24:54-61.

8. Gehring $\mathrm{U}$, Wijga $\mathrm{AH}$, Brauer $\mathrm{M}$, et al. Traffic-related air pollution and the development of asthma and allergies during the first 8 years of life. Am J Respir Crit Care Med 2010;181:596-603.
9. Ranzi A, Porta D, Badaloni C, et al. Exposure to air pollution and respiratory symptoms during the first 7 years of life in an Italian birth cohort. Occup Environ Med 2014;71:430-6.

10. Lindgren A, Stroh E, Björk J, et al. Asthma incidence in children growing up close to traffic: a registry-based birth cohort. Environ Health 2013;12:91.

11. Ministry of Land, Infrastructure, Transport and Tourism, Japan. FY 1999 Road Traffic Census. 2000. http://www.r-census.ne.jp/ h11cdsupport (accessed 19 Feb 2016) (in Japanese).

12. Ministry of Internal Affairs and Communications, Japan. Grid Square Statistics of 2000 Population Census. 2003. http://www.stat.go.jp/ data/mesh/teikyo.htm (accessed 19 Feb 2016) (in Japanese).

13. Ferris BG. Epidemiology Standardization Project (American Thoracic Society). II. Recommended respiratory disease questionnaires for use with adults and children in epidemiological research. Am Rev Respir Dis 1978;118(Suppl 6):7-15.

14. Shima $M$, Mae $H$, Odajima $H$, et al. Evaluation of the validity of a bronchial asthma questionnaire for children under 2 years of age, Japan. J Pediatr Allergy Clin Immunol 2007;21:311-18 (in Japanese).

15. Morikawa A, Nishima S. New Japanese pediatric guidelines for the treatment and management of bronchial asthma. Pediatr Int 2007;49:1023-31.

16. White JE. A two stage design for the study of the relationship between a rare exposure and a rare disease. Am J Epidemiol 1982;115:119-28.

17. Breslow NE, Cain KC. Logistic regression for two-stage case-control data. Biometrika 1988;75:11-20.

18. Polzius $\mathrm{R}$, Wuske $\mathrm{T}$, Mahn J. Wipe test for the detection of indoor allergens. Allergy 2002;57:143-5.

19. Kanda I, Ohara T, Nataami T, et al. Development of outdoor exposure model of traffic-related air pollution for epidemiologic research in Japan. J Expo Sci Environ Epidemiol 2013;23:487-97.

20. Environmental Research and Control Center. Manual for regulation of total emission of nitrogen oxides. Tokyo: Environmental Research and Control Center 2000 (in Japanese).

21. Highway Environmental Research Institute. Environmental impact assessment technique for road 2000, vol. 2. Tokyo: Highway Environmental Research Institute 2000 (in Japanese).

22. Zhao LP, Lipsitz S. Designs and analysis of two-stage studies. Stat Med 1992;11:769-82.

23. Yamazaki S, Shima M, Nakadate $T$, et al. Association between traffic-related air pollution and development of asthma in schoo children: cohort study in Japan. J Expo Sci Environ Epidemiol 2014;24:372-9.

24. Oftedal B, Nystad W, Brunekreef B, et al. Long-term traffic-related exposures and asthma onset in schoolchildren in Oslo, Norway. Environ Health Perspect 2009;117:839-44.

25. Burke W, Fesinmeyer M, Reed K, et al. Family history as a predictor of asthma risk. Am J Prev Med 2003;24:160-9.

26. Subbarao P, Mandhane PJ, Sears MR. Asthma: epidemiology, etiology and risk factors. CMAJ 2009;181:E181-90.

27. Bröms K, Norbäck D, Sundelin C, et al. A nationwide study of asthma incidence rate and its determinants in Swedish pre-school children. Eur J Epidemiol 2012;27:695-703.

28. Hasunuma $\mathrm{H}$, Ishimaru $\mathrm{Y}$, Yoda $\mathrm{Y}$, et al. Decline of ambient air pollution levels due to measures to control automobile emissions and effects on the prevalence of respiratory and allergic disorders among children in Japan. Environ Res 2014;131:111-18.

29. Ministry of the Environment Government of Japan. FY 2009 Annual Report of Environmental Health Surveillance for Air Pollution. 2011. http://www.env.go.jp/en/headline/headline.php?serial=1756 (accessed 26 Jan 2015). 